\title{
Sepsis por fístula paraprotésico entérica
}

\author{
Sepsis due to enteric paraprosthetic fistula
}

Gabriel España C. ${ }^{1}$, Daniel Moreno M. ${ }^{1}$, Camilo Urzúa E. ${ }^{1}$, Victoria García-Prieto B. ${ }^{1}$, María Rubio M. ${ }^{1}$ y Nadia Serrano F. ${ }^{1}$

Paciente masculino de 81 años, con antecedentes de aneurisma aórtico infrarenal tratado endovascularmente (endoprótesis aortofemoral y bypass femoro-femoral).

Paciente consulta por cuadro de tres días de evolución de fiebre hasta $39^{\circ} \mathrm{C}$ y deposiciones melénicas. Exámenes de laboratorio objetiva SIRS. Se inicia antibioterapia de amplio espectro, endoscopía digestiva alta negativa. TC muestra íntima relación de cuarta porción del duodeno con pared de aneurisma aórtico, además, de gas en relación a hematoma residual periprotésico. Estudio contrastado objetiva fístula desde cuarta porción del duodeno a espacio aneurismático periprotésico-aortico.

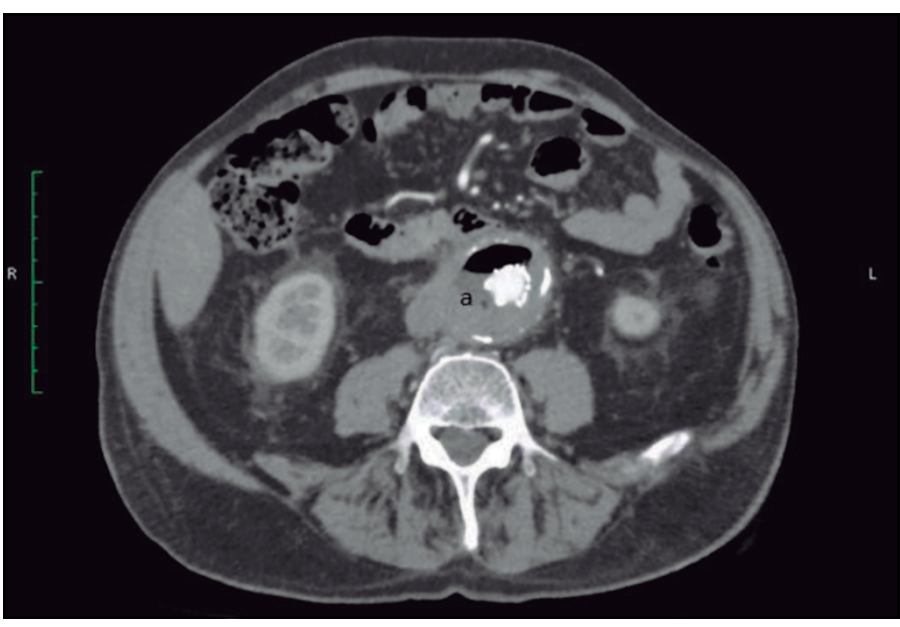

Figura 1. TC Abdomen: a. Se observa flujo de contraste por dispositivos endovasculares, que se encuentran permeables, disminución del saco aneurismático respecto a controles anteriores. Contacto del saco aneurismático con $4^{\circ}$ porción del duodeno asociado a inflamación periaórtica y gas en cara anterior del saco, con sospecha de fístula aortoentérica versus infección del dispositivo endovascular.

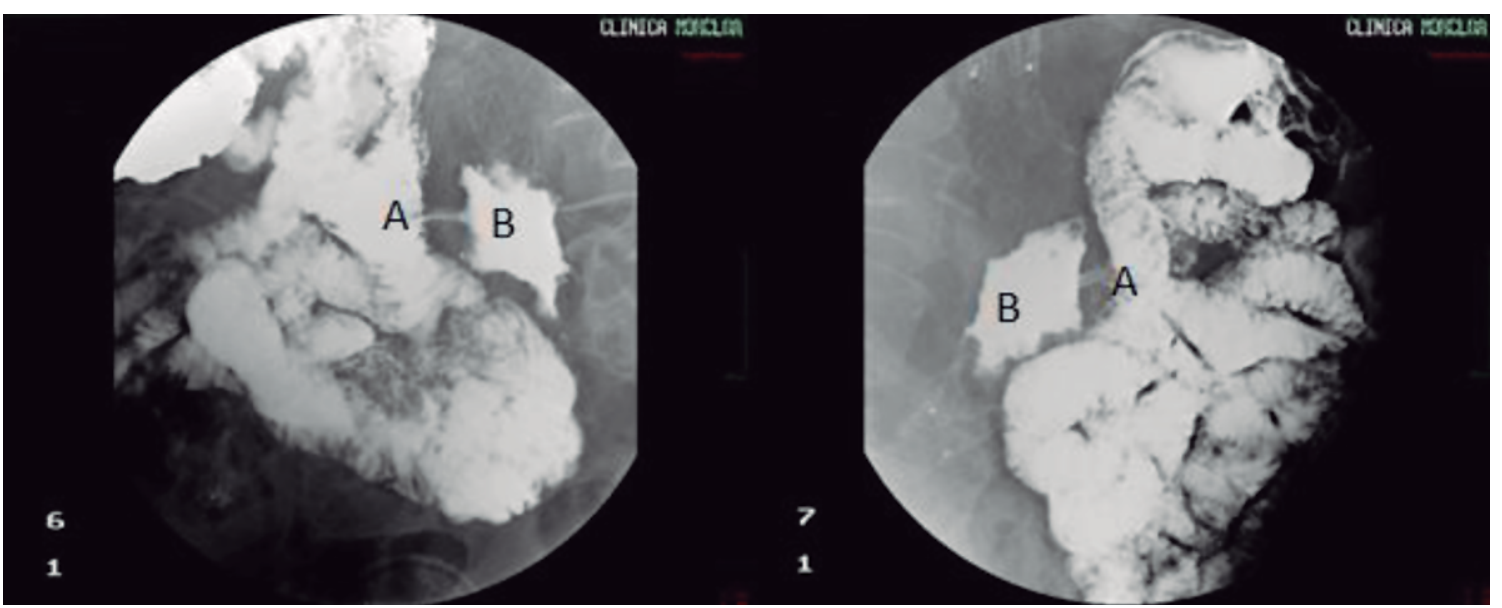

Figura 2. Estudio contrastado digestivo alto, A. Contraste de bario pasa en la cuarta porción del duodeno desde el lumen al espacio periaórtico. B. Se logra observar en placa endoprótesis aórtica, contraste en espacio periprotésico y trayecto fistuloso. 


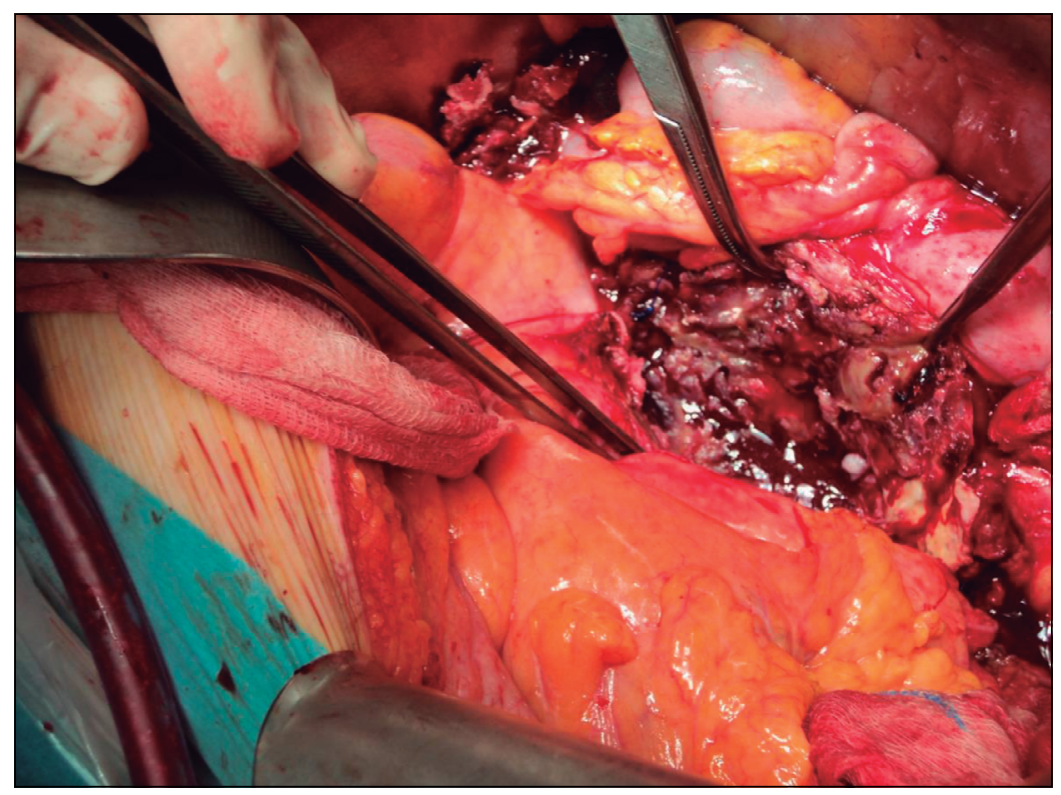

Figura 3. Fotografía de sitio operatorio, tejido desvitalizado e infectado correspondiente a hematoma periaórtico infectado. Visión tras explantación de endoprótesis.
Se realiza bypass extraanatómico desde arteria axilar derecha a bypass fémoro-femoral y explantación de prótesis aórtica infectada. Buena respuesta a tratamiento, alta a los 10 días.

Los factores mecánicos serían los principales causantes en la formación de las fístulas aortoentéricas secundarias. La falta de separación del intestino con el saco aneurismático y la fricción del mismo con la pared intestinal permitirían la formación de la fístula, asociado a esto otros factores mecánicos ${ }^{1-5}$. La presentación clínica clásica es la hemorragia digestiva (tipo sangrado centinela), seguido por la infección e isquemia aguda de miembros inferiores. Es fundamental la alta sospecha clínica. El tratamiento es la extirpación de la prótesis infectada, pero está asociado a alta morbimortalidad ${ }^{6-9}$.

Financiamiento: No se recibieron aportes financieros para la realización de este trabajo.

Conflictos de interés: ninguno.

\section{Referencias}

1. Sanchis García JM, Molina Fábrega R, La Parra Casado C, Naranjo Romaguera P, Palmero da Cruz J. Fístulas aortoentéricas primarias: presentación de dos casos y revisión de la literatura. Revista Argentina de Radiología [Internet]. 2007;71(4):4237. Recuperado de: http://www.redalyc.org/ articulo.oa?id=382538456006.

2. Martínez AE, Acín F, March J, Medina FJ, de Haro J, Flórez A. Reparación de las fístulas aortoentéricas secundarias. Revisión sistemática. Cir Esp. 2007;82:321-7. DOI: 10.1016/S0009739X(07)71740-2.

3. Tracci MC, Cherry Jr KJ. Chapter 62: THE AORTA En: Sabiston Textbook of surgery. The biological Basis of Modern Surgical Practice 19th. Editorial: Elsevier Saunders. 2012; p. 1697-708.

4. O'Connor S, Andrew P, Batt M,
Becquemin JP. A systematic review and meta-analysis of treatments for aortic graft infection Jour Vasc Surg. 2006; 44:38-45.

5. Jones J, Atkins M, Brewster D, Chung T, Kwolek C, LaMuraglia G, et al. Persistent type 2 endoleak after endovascular repair of abdominal aortic aneurysm is associated with adverse late outcomes.

J Vasc Surg. 2007;46:1-8.

6. Burks JA Jr, Faries PL, Gravereaux EC, Hollier LH, Marín ML. Endovascular repair of bleeding aortoenteric fistulas: a 5-year experience. J Vasc Surg. 2001;34:1055-9. DOI: 10.1067/ mva.2001.119752.

7. Kuestner LM, Reilly LM, Jicha DL, Ehrenfeld WK, Goldstone J, Stoney RJ. Secondary aortoenteric fistula: contemporary outcome with use of extraanatomic bypass and infected graft excision. J Vasc Surg. 1995;21:184-95; discussion 195-6. Disponible en: http:// www.jvascsurg.org/article/S07415214(95)70261-X/fulltext.

8. Riera del Moral L, Fernández Alonso S, Stefanov Kiuri S, Fernández Caballero D, Fernández Heredero A, Gutiérrez Nistal $\mathrm{M}$, et al. Aortoenteric Fistula Arising as a Complication of Endovascular Treatment of Abdominal Aortic Aneurysm. Annals of Vascular Surgery 2009;23:255.e13-255. e17.

9. Bergoeing M, Mertens R, Mariné L, Valdés F, Kramer A, Nervi B, et al. Tratamiento endovascular de fístula aorto esofágica secundaria a cáncer de esófago: Caso clínico. Rev Med Chile [Internet]. $2013 \mathrm{Feb}$ [citado el 30 de diciembre de 2017];141(2):264-7. Disponible en: http://www.scielo.cl/ scielo.php?script=sci_arttext\&pid=S003498872013000200018\&lng=es. http://dx.doi.org/10.4067/S003498872013000200018 . 